
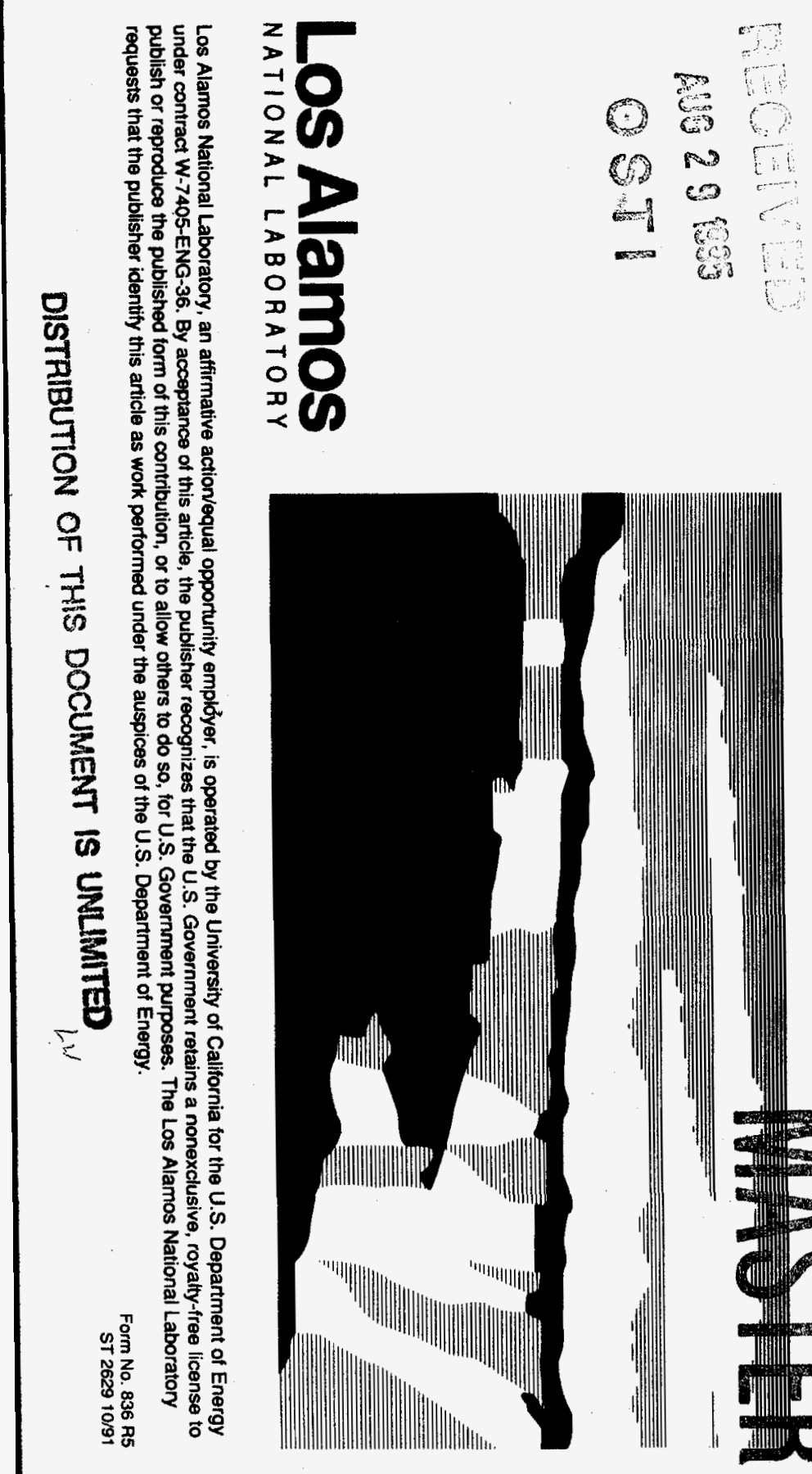

DISCLAIMER

This report was prepared as an account of work sponsored by an agency of the United States Government. Neither the United States Government nor any agency thereof, nor any of their employees, makes any warranty, express or implied, or assumes any legal liability or responsibility for the accuracy, completeness, or usefulness of any information, apparatus, product, or process disclosed, or represents that its use would not infringe privately owned rights. Reference herein to any specific commercial product, process, or service by trade name, trademark, manufacturer, or otherwise does not necessarily constitute or imply its endorsement, recommendation, or favoring by the United States Government or any agency thereof. The views and opinions of authors expressed herein do not necessarily state or reflect those of the United States Government or any agency thereof.

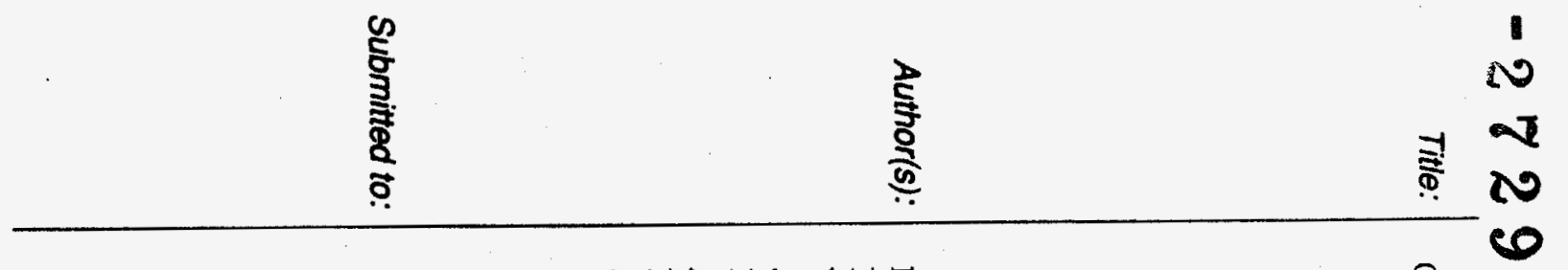

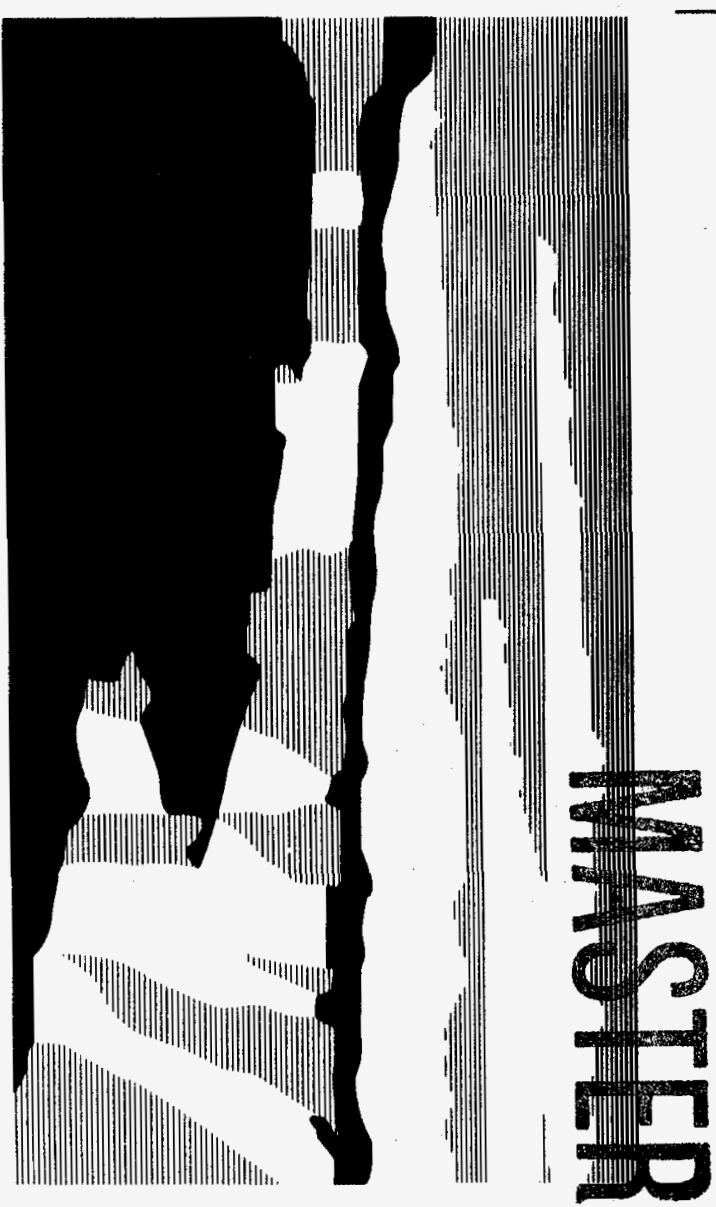

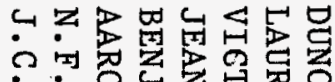

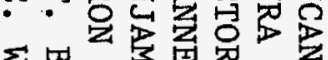

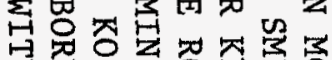

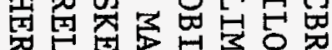

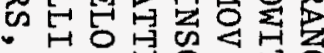

团思是是

要

罗

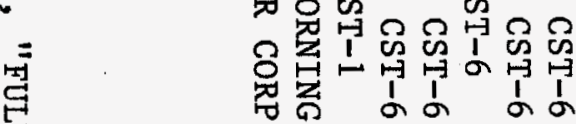

䒺

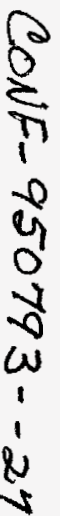




\section{DISCLAIMER}

Portions of this document may be illegible in electronic image products. Images are produced from the best available original document. 


\title{
Optical limiting and excited-state absorption in fullerene solutions and doped glasses
}

\author{
D. McBranch, L. Smilowitz, V. Klimov, A. Koskelo, J. M. Robinson, and B. R. Mattes \\ Chemical Science and Technology Division \\ Los Alamos National Laboratory, Los Alamos, NM 87545 \\ J. C. Hummelen and F. Wudl \\ University of California, Santa Barbara, CA 93106 \\ J. C. Withers \\ MER Corporation, Tucson, AZ 85706 \\ N. F. Borrelli \\ Corning Inc., Corning, NY 14831
}

\begin{abstract}
We report the ground-state and excited-state optical absorption spectra in the visible and near infrared for several substituted fullerenes and higher fullerenes in toluene solutions. Based on these measurements, broadband predictions of the optical limiting performance of these molecules can be deduced. These predictions are then tested in the wavelength range from $532 \mathrm{~nm}$ to $700 \mathrm{~nm}$ in intensity-dependent transmission measurements. We observe optical limiting in all fullerenes measured; higher fullerenes show the greatest potential for limiting in the near infrared (650-1000 nm), while substituted $\mathrm{C}_{60}$ shows optimal limiting in the visible (450-700 nm). We observe dramatically reduced limiting for solid forms of $\mathrm{C}_{60}$ (thin films and $\mathrm{C}_{60}$-doped porous glasses), indicating that efficient optical limiting in fullerenes requires true molecular solutions.
\end{abstract}

\section{INTRODUCTION}

Fullerenes have attracted much recent interest for their potential to act as optical limiters of high fluence pulsed lasers. ${ }^{1-7}$ The excited-state absorption cross-section for $\mathrm{C}_{60}$ is much larger than that in the ground-state, both in the singlet and triplet manifolds. ${ }^{8-10}$ This property results in significant additional absorption in the visible and near infrared spectral region, developing on a picosecond timescale, after photoexcitation into the lowest singlet state. ${ }^{4}$ This reverse saturable absorption (RSA), or optical limiting, phenomenon may be very useful for eye and sensor protection from pulsed laser light.

Previous studies have measured optical limiting only in a limited selection of fullerenes $\left(\mathrm{C}_{60}\right.$ and $\left.\mathrm{C}_{70}\right)$ and only 
at $532 \mathrm{~nm} \cdot{ }^{1-7}$ In this work, we report a survey of the optical limiting performance for several substituted fullerenes and higher fullerenes in toluene solution in the visible to near-infrared spectral regions $(500-1000 \mathrm{~nm})$. Excited-state absorption spectra are measured with picosecond resolution using time-resolved pump-probe absorption. This allows broadband predictions of the optical limiting performance. These predictions are then tested at selected wavelengths from $532-700 \mathrm{~nm}$ by measuring intensity-dependent transmission. We find that $\mathrm{C}_{60}$ and substituted derivatives of $\mathrm{C}_{60}$ display optical limiting from $532-700 \mathrm{~nm}$, with the limiting performance increasing to the infrared, constrained by the vanishing ground-state absorption below $700 \mathrm{~nm}$. Higher fullerenes $\left(\mathrm{C}_{78}, \mathrm{C}_{84}\right)$ also show optical limiting in this range, with further potential for limiting out to $1000 \mathrm{~nm}$. Comparisons of optical limiting and excited-state absorption in solid forms of $\mathrm{C}_{60}$ (thin films and doped porous glasses) show that the much faster relaxation dynamics in the solid reduces the limiting effectiveness for nanosecond pulses. Hence, optimal use of fullerenes for optical limiting in a solid form will require that the fullerenes be microscopically dispersed in a solid host matrix. ${ }^{2,7,11}$

\section{EXPERIMENTAL}

Toluene solutions of $\mathrm{C}_{60}$, substituted derivatives of $\mathrm{C}_{60}\left[\mathrm{C}_{60}-\mathrm{C}_{2} \mathrm{H}_{5} \mathrm{~N}, 2\left[\left(\eta^{2}-\mathrm{C}_{\mathrm{p}}\right)_{2} \mathrm{Fe}\right] \mathrm{C}_{60}\right.$ (Ferrocene- $\mathrm{C}_{60}$ ), ar $\mathrm{I}_{4}$ phenyl- $\mathrm{C}_{61}$-butyric acid cholestryl ester (PCBCR)] and higher fullerenes $\left(\mathrm{C}_{70}, \mathrm{C}_{78}\right.$, and $\left.\mathrm{C}_{84}\right)$ were prepared in 2 $\mathrm{mm}$ path length optical cells. PCBCR was synthesized by a method which will be published elsewhere. ${ }^{12}$ Other materials were provided by MER Corp. Concentrations for $\mathrm{C}_{60}$, Ferrocene- $\mathrm{C}_{60}$, PCBCR, and $\mathrm{C}_{70}$ were 0.15 wt\%, $0.15 \mathrm{wt} \%, 0.21 \mathrm{wt} \%$, and $.04 \mathrm{wt} \%$, respectively. These concentrations were chosen to yield transmissions in the range of $20 \%-80 \%$ in the visible and near-infrared. The other materials $\left(\mathrm{C}_{78}, \mathrm{C}_{84}\right.$ and $\left.\mathrm{C}_{60}-\mathrm{C}_{2} \mathrm{H}_{5} \mathrm{~N}\right)$ were prepared as saturated solutions of uncalibrated concentration, due to limited solubility. Thin films of $\mathrm{C}_{60}$ were prepared by sublimation in vacuum $\left(10^{-6} \mathrm{Torr}\right) . \mathrm{C}_{60}$-doped porous $\mathrm{SiO}_{2}$ glasses with $28 \%$ porosity and an average pore size of 4-6 $\mathrm{nm}$ (Corning Vycor brand ${ }^{13}$ ) were prepared by dipping in saturated $\mathrm{C}_{60}$-toluene solution, followed by vacuum drying, to form a solid-state matrix with $\mathrm{C}_{60}$ deposited along the insides of the glass pores. ${ }^{14}$

Time-resolved excited-state absorption spectra were measured using a femtosecond (fs) pump-probe technique. The samples were excited at $397 \mathrm{~nm}(3.12 \mathrm{eV})$ by 200 fs pulses from a regeneratively amplified modelocked Ti:Sapphire laser. The pump pulse energy was $5 \mu \mathrm{J}$, corresponding to an excitation density of $12 \mathrm{~mJ} / \mathrm{cm}^{2}$, and the repetition rate was $1 \mathrm{kHz}$. Femtosecond white light pulses were generated in a $1 \mathrm{~cm}$ water cell. The transmission at the sample was measured using a $.15 \mathrm{~m}$ spectrometer and CCD array with the pump beam on $\left(\mathrm{T}_{\text {on }}\right)$ and off $\left(\mathrm{T}_{\text {off }}\right)$. The differential transmission $\Delta \mathrm{T} / \mathrm{T}$ was determined from the expression $\Delta \mathrm{T} / \mathrm{T}=\left(\mathrm{T}_{\text {on }}-\mathrm{T}_{\text {off }}\right) / \mathrm{T}_{\text {off }}$. Each spectrum was the average of $500-1000$ pulses.

Optical limiting (intensity-dependent transmission) measurements were made using a frequency-doubled Nd:YAG laser (Quanta Ray GCR-3) at $532 \mathrm{~nm}$, and pulsed dye laser (Quanta Ray PDL-3) from 560-700 nm. The 6 ns pulses were split into reference and signal beams, and the signal beam was focused with a $150 \mathrm{~mm}$ lens onto the sample, to a radius of $\approx 10 \mu \mathrm{m}$ (measured by scanning a knife edge across the beam). The transmitted light was collimated and sent onto a large area silicon photodiode. The signal and reference photodiodes were connected to a Stanford Research boxcar averager and computer for signal averaging. Each data point was an average of 20-50 individual laser pulses, and the beam spot was kept fixed through each data set. The incident energy was measured directly, and the input fluences were calibrated by measuring the two-photon absorption response of a $\mathrm{ZnSe}$ reference. ${ }^{15}$ This calibration yielded an effective beam area at $575 \mathrm{~nm}$ of $4.2 \times 10^{-6} \mathrm{~cm}^{2}$, consistent with the knife edge measurement; separate calibrations were performed at each wavelength measured. The laser fluence was ramped up first, and then an identical data set taken while ramping the fluence back down, to check for optical damage and slow thermal effects. Open aperture Z-scans were performed by fixing the incident fluence and scanning the sample through the focus. ${ }^{16}$ This allowed a direct determination of the effective two-photon absorption coefficient $\beta$ relative to $\mathrm{ZnSe}$ at fluences well below the damage threshold. 


\section{RESULTS AND DISCUSSION}

Figure 1(a) shows the ground-state optical absorption spectra for $\mathrm{C}_{60}$ and higher fullerenes from $400-750 \mathrm{~nm}$. The absorption feature in $\mathrm{C}_{60}$ in this range corresponds to the lowest optical transition, a dipole-forbidden even parity transition which is weakly allowed by Herzberg-Teller coupling to the vibrational modes of the molecule. ${ }^{17}$ This symmetry specific feature is one factor governing the optical limiting efficiency in fullerenes. As the icosohedral symmetry of $\mathrm{C}_{60}$ is altered in going to higher fullerenes, this lowest transition is no longer symmetry forbidden, and significant absorption can be observed if the symmetry breaking mixes in strong transition moments. For example, the ground-state absorption cross section for $\mathrm{C}_{70}$ in this region is up to ten times higher than that of $\mathrm{C}_{60}$ (the concentration of the $\mathrm{C}_{70}$ solution is $0.25 \times$ that of the $\mathrm{C}_{60}$ solution). Consequently, the limiting effectiveness for wavelengths shorter than $\approx 600 \mathrm{~nm}$ (the wavelength below which the ground-state absorption increases sharply) is expected to decrease in the higher fullerenes, as observed in $\mathrm{C}_{70}$ at $532 \mathrm{~nm} .{ }^{1}$ For wavelengths longer than $\approx 600 \mathrm{~nm}$ in $\mathrm{C}_{78}$ and $\mathrm{C}_{84}$, there is a broad absorption tail extending to beyond $1000 \mathrm{~nm}$. Figure $1(\mathrm{~b})$ shows the ground-state optical absorption spectra for substituted derivatives of $\mathrm{C}_{60}$. The Ferrocene- $\mathrm{C}_{60}$ derivative has a spectrum nearly identical to that of $\mathrm{C}_{60}$, indicating that the weakly bound coordinative complex does not influence the symmetry of the $\pi$-electrons on the $\mathrm{C}_{60}$. Both PCBCR and $\mathrm{C}_{60}-\mathrm{C}_{2} \mathrm{H}_{5} \mathrm{~N}$ consist of a single substitution across a double bond joining two hexagons in the $\mathrm{C}_{60}$, resulting in the loss of two $\pi$-electrons and a corresponding loss of icosohedral symmetry. However, the primary result of the single substitution is that the spectrum is shifted and broadened, with the appearance of a new vibronic-coupled band in the region of $650-720 \mathrm{~nm}$. The magnitude of the transition dipole moment remains small in the region $450-700 \mathrm{~nm}$, despite the symmetry breaking; the excited-state wavefunction retains most of the character found in pure $\mathrm{C}_{60}$.
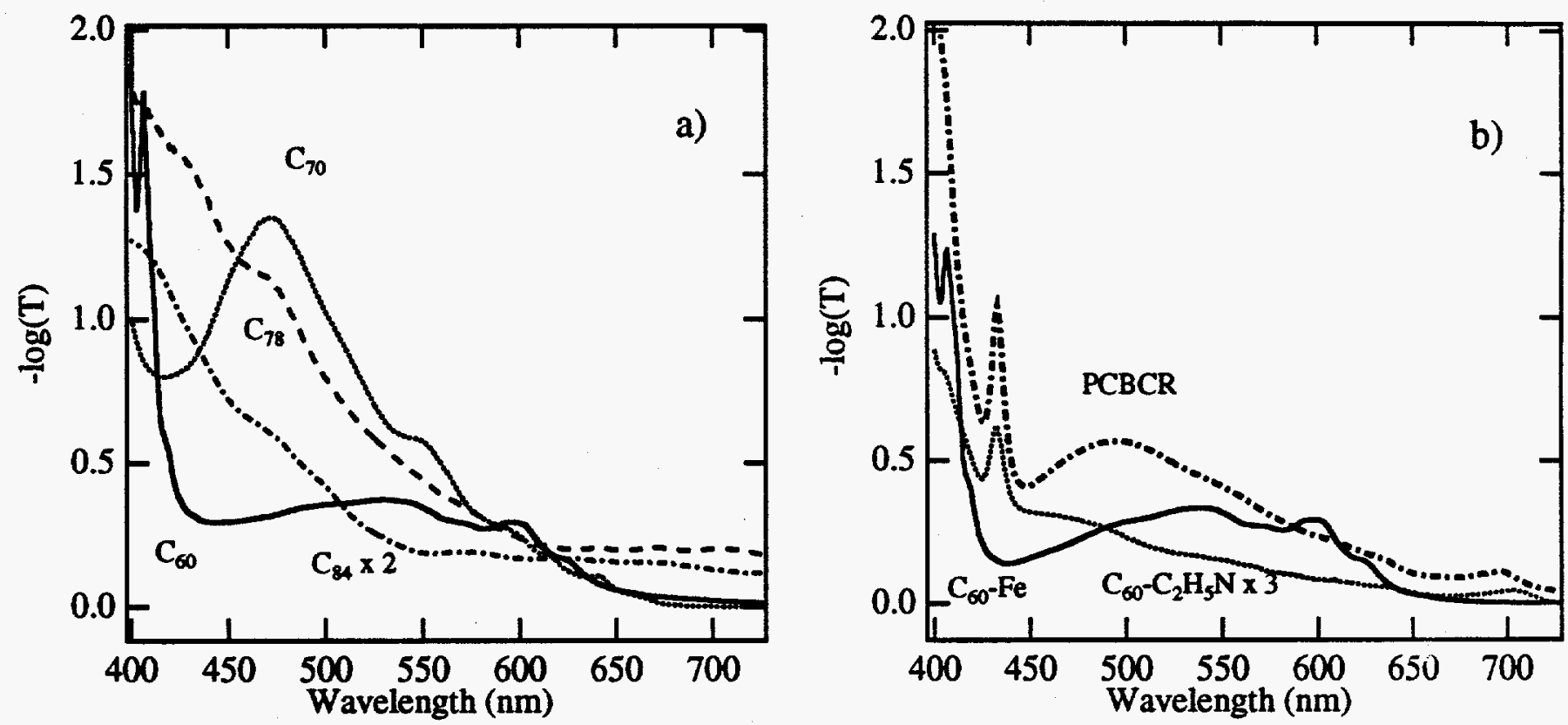

Figure 1. Ground-state absorption spectra for a) $\mathrm{C}_{60}$ (solid line) and higher fullerenes $\left(\mathrm{C}_{70}\right.$, dotted line; $\mathrm{C}_{78}$, dashed line; $\mathrm{C}_{84}$, dash-dot line) and $\mathrm{b}$ ) substituted $\mathrm{C}_{60}$ derivatives (Ferrocene- $\mathrm{C}_{60}$, solid line; $\mathrm{C}_{60}-\mathrm{C}_{2} \mathrm{H}_{5} \mathrm{~N}$, dotted line; PCBCR, dash-dot line).

The criterion for optical limiting due to RSA is simple: the ratio of the excited-state absorption cross section $\sigma^{*}$ to the ground state absorption cross section $\sigma_{0}$ must be greater than one. ${ }^{18}$ In addition, the ground state absorption cross section must be finite in order to access the strong excited-state absorptions. For a transient absorption experiment (in the limit that the pump beam is absorbed in a thickness smaller than the pump/probe interaction 
length), the differential transmission is directly proportional to the excited-state absorption cross section $\sigma^{*}$ :

$$
-\frac{\Delta \mathrm{T}}{\mathrm{T}} \approx \sigma^{*} \mathrm{~N}_{\text {punip }}\left(-\frac{\Delta \mathrm{T}}{\mathrm{T}} \ll 1\right)
$$

where $\mathrm{N}_{\text {pump }}$ is the pump beam photon flux. Hence the time-resolved excited-state transmission experiment provides a direct measure of $\sigma^{*}$. For our photon flux $\left(\mathrm{N}_{p u m p} \approx 2.4 \times 10^{16} \mathrm{~cm}^{-2}\right)$ we obtain the conversion:

$$
-\frac{\Delta \mathrm{T}}{\mathrm{T}}=0.1 \Longleftrightarrow \sigma^{*}=4.2 \times 10^{-18} \mathrm{~cm}^{2} \text {. }
$$

This is a lower limit, assuming perfect geometric overlap of the pump and probe beams.
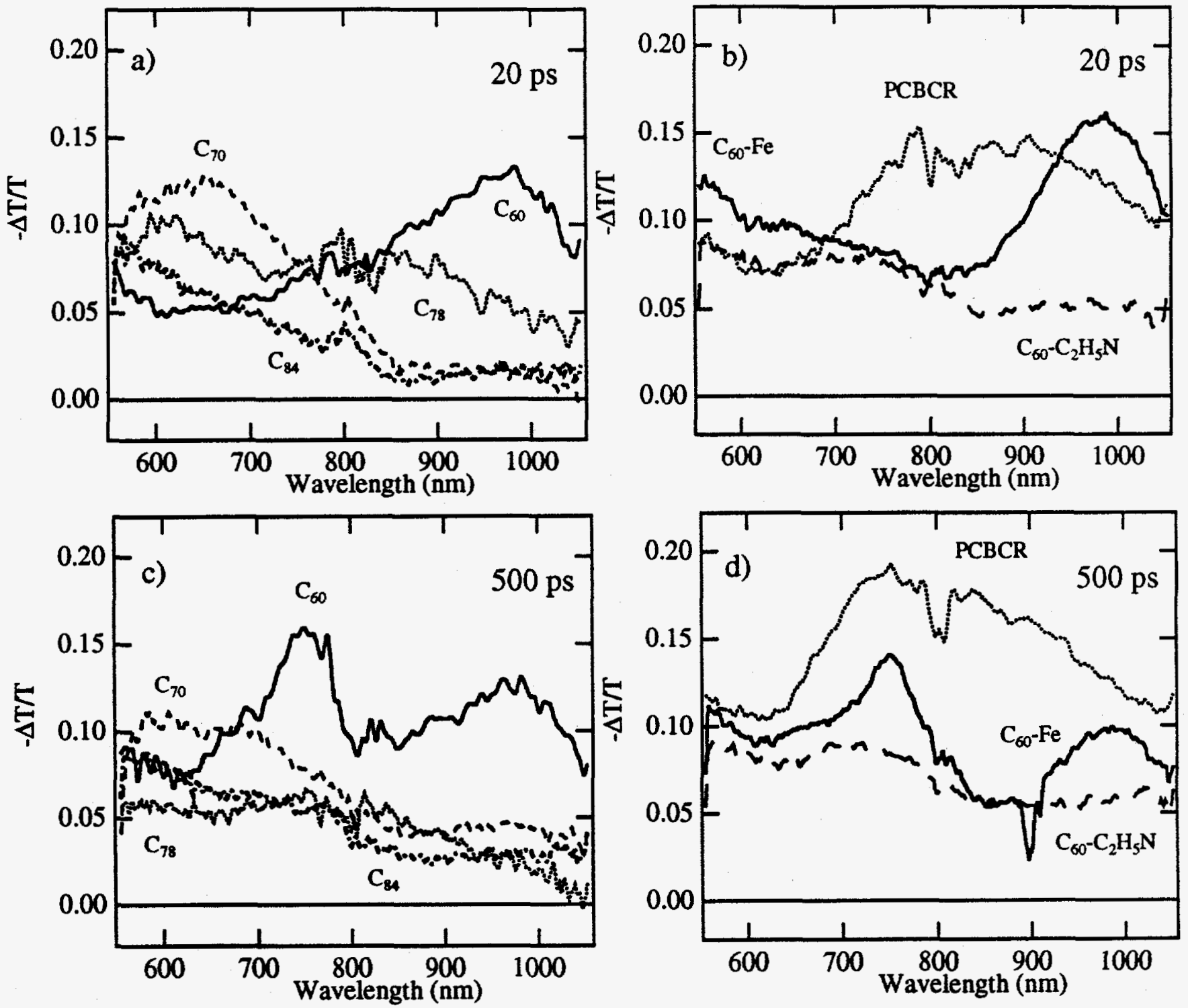

Figure 2. Excited-state absorption $-\Delta T / T$. $C_{60}$ (solid line) and higher fullerenes $\left(C_{70}\right.$, dashed line; $C_{78}$, dotted line; $\mathrm{C}_{84}$, dashed-dotted line) at a) $20 \mathrm{ps}$, and c) $500 \mathrm{ps}$. Substituted $\mathrm{C}_{60}$ derivatives (Ferrocene$\mathrm{C}_{60}$, solid line; $\mathrm{C}_{60}-\mathrm{C}_{2} \mathrm{H}_{5} \mathrm{~N}$, dashed line; $\mathrm{PCBCR}$, dotted line) at b) $20 \mathrm{ps}$, and d) $500 \mathrm{ps}$.

Figure 2 shows the excited-state absorption spectra $-\Delta T / T$ for $C_{60}$, higher fullerenes, and substituted $C_{60}$, at short times (20 ps) following photoexcitation, and at longer times (500 ps). In Fig. 2(c) the triplet absorption peak in 
$\mathrm{C}_{60}$ at $750 \mathrm{~nm}$ is clearly evident. ${ }^{8}$ The spectral features for both the substituted and higher fullerenes are broadened relative to $\mathrm{C}_{60}$ and the weakly bound complex Ferrocene- $C_{60}$. The excited-state absorption for the higher fullerenes gradually decreases at progressively longer wavelengths $(>600 \mathrm{~nm})$, both at short and long times; the ground-state absorption cross section also gradually decreases over the same wavelength range. For $\mathrm{C}_{78}$ and $\mathrm{C}_{84}$, there is a small but finite absorption throughout the range from 600-1000 nm. Hence, it is expected from this measurement that the optimal wavelength range for limiting in the higher fullerenes will be in the range from $600-1000 \mathrm{~nm}$. The two substituted derivatives PCBCR and $\mathrm{C}_{60}-\mathrm{C}_{2} \mathrm{H}_{5} \mathrm{~N}$ show similar broad excited-state spectra at short and long times. For optical limiting applications, inhomogeneous broadening of spectral features can be an advantage, since uniform wavelength response is desirable. At both short and long times, $\sigma^{*}$ increases over the wavelength range $500-700 \mathrm{~nm}$ in which the ground-state absorption is small but finite, and decreasing. Thus, as for pure $\mathrm{C}_{60}{ }^{8}$ the ratio $\sigma^{*} / \sigma_{0}$ grows larger for wavelengths longer than $532 \mathrm{~nm}$. These conclusions are consistent with independent measurements by Heflin et al. ${ }^{19}$

The signal magnitudes are not corrected for different absorption depths at the pump wavelength of $397 \mathrm{~nm}(3.12$ $\mathrm{eV}$ ). For direct comparison between compounds of the excited-state absorption in the more dilute solutions (especially $\mathrm{C}_{84}$ and $\mathrm{C}_{60}-\mathrm{C}_{2} \mathrm{H}_{5} \mathrm{~N}$ ), this correction should be made. This requires detailed knowledge of the pump and probe beam overlap in the sample. From the measured $200 \mu \mathrm{m}$ pump beam spot size, and the $5^{\circ}$ angle between pump and probe beams, we estimate an overlap region of $\approx 1 \mathrm{~mm}$. The correction takes into account the percentage of the pump beam photons which are absorbed in this interaction volume. For $\mathrm{C}_{84}$, the observed spectra should be multiplied by approximately 1.8, and for $\mathrm{C}_{60}-\mathrm{C}_{2} \mathrm{H}_{5} \mathrm{~N}$ the factor is 2.1 . Hence, for all the fullerenes observed, there are large and broadband photoinduced absorption features which provide a mechanism for broadband RSA optical limiting.
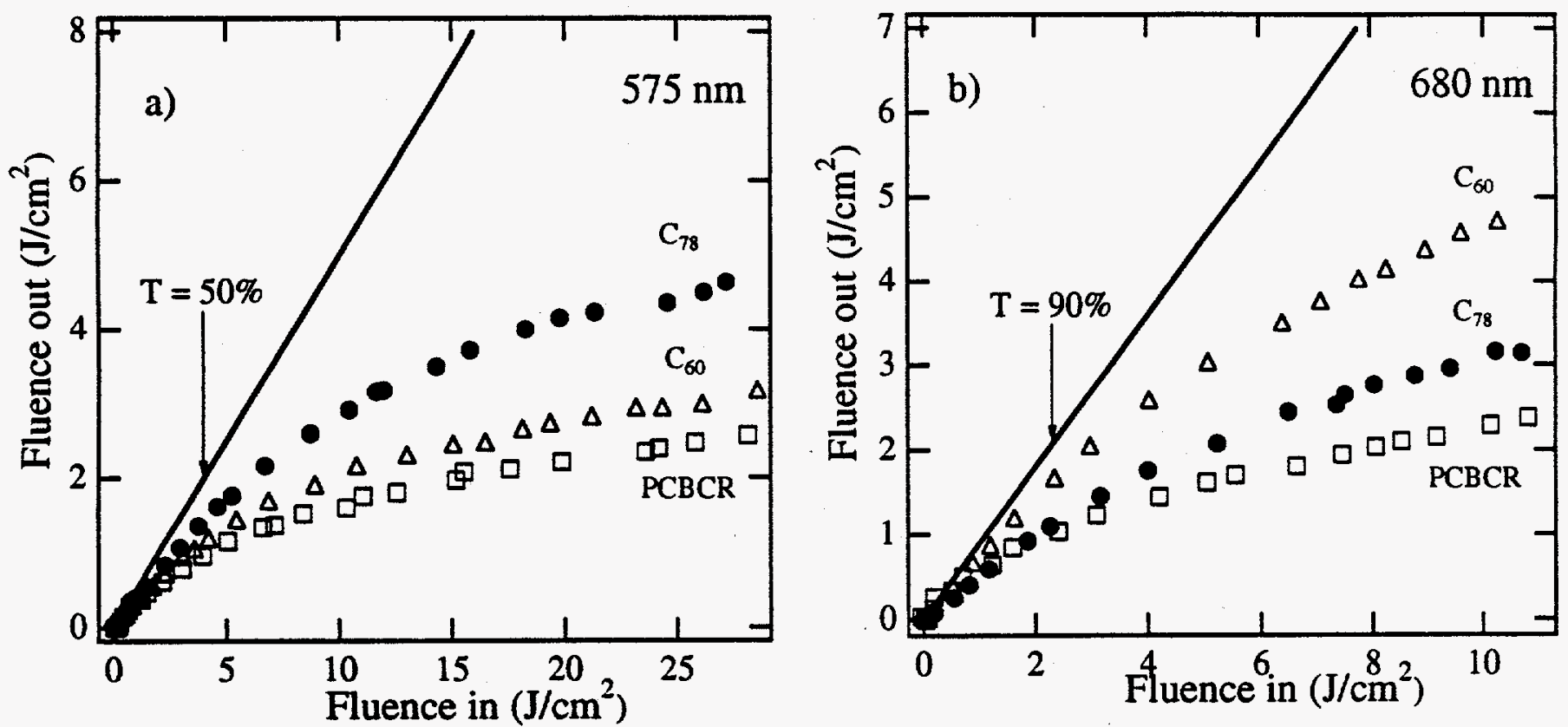

Figure 3. Intensity-dependent transmission for $\mathrm{C}_{60}$ (open triangles), $\mathrm{C}_{78}$ (closed circles), and $\mathrm{PCB}$ ( ' $k$ (open squares) at a) $575 \mathrm{~nm}$, and b) $680 \mathrm{~nm}$. The low fluence transmittances (corrected for refleci. n) for $\mathrm{C}_{60}, \mathrm{C}_{78}$, and PCBCR, respectively, are $50 \%, 44 \%$, and $57 \%$ at $575 \mathrm{~nm}$, and $91 \%, 67 \%$, and $87 \%$ at $680 \mathrm{~nm}$.

Given that all fullerenes measured satisfy the condition for optical limiting over some wavelength range, the primary practical considerations for using these materials revolve around two issues: 1) how broad and flat is the wavelength range over which these materials are effective; 2 ) how soluble are the materials. The two materials most promising from this standpoint are $\mathrm{PCBCR}$, and $\mathrm{C}_{78}$. PCBCR is approximately ten times more soluble than $\mathrm{C}_{60}$ in common organic solvents, with a small but finite ground-state absorption which extends past $700 \mathrm{~nm}$. $\mathrm{C}_{78}$, which is substantially more soluble than $\mathrm{C}_{\mathbf{8 4}}$, has broad (small) ground-state and (large) excited-state absorptions extending 
from $600-1000 \mathrm{~nm}$. In the following, we examine the predictions obtained from the excited-state transient absorption for these specific materials using intensity-dependent transmission measurements.

Figure 3 compares the intensity-dependent transmission curves for $\mathrm{C}_{60}, \mathrm{C}_{78}$, and PCBCR at $575 \mathrm{~nm}$ (Fig. 3(a)), and $680 \mathrm{~nm}$ (Fig. 3(b)). As expected for an RSA mechanism, the curves display a shoulder with a transition from a linear intensity dependence of the transmission at lower fuences, to linear dependence at higher fluence with smaller slope, corresponding to the higher excited-state absorption. At $575 \mathrm{~nm}$, the low fluence linear transmission of all three samples is similar ( $50 \%, 44 \%$, and $57 \%$ for $\mathrm{C}_{60}, \mathrm{C}_{78}$, and $\mathrm{PCBCR}$, respectively). Inspection of the excited-state absorption spectra in Fig. 2 indicates that $\sigma^{*}$ increases at this wavelength going from $\mathrm{C}_{78}$ to $\mathrm{C}_{60}$ to PCBCR. This same result is observed in the optical limiting comparison in Fig. 3(a). By contrast, at $680 \mathrm{~nm}$, the linear absorption of $\mathrm{C}_{60}$ is very small, so that the excited-state is not sufficiently populated to activate the RSA, despite the large $\sigma^{*}$. For $\mathrm{C}_{78}$ and PCBCR, substantially better limiting effectiveness is observed, as expected. For wavelengths longer than $700 \mathrm{~nm}$, the PCBCR does not absorb sufficiently, and $\mathrm{C}_{78}$ should be a better limiting material.

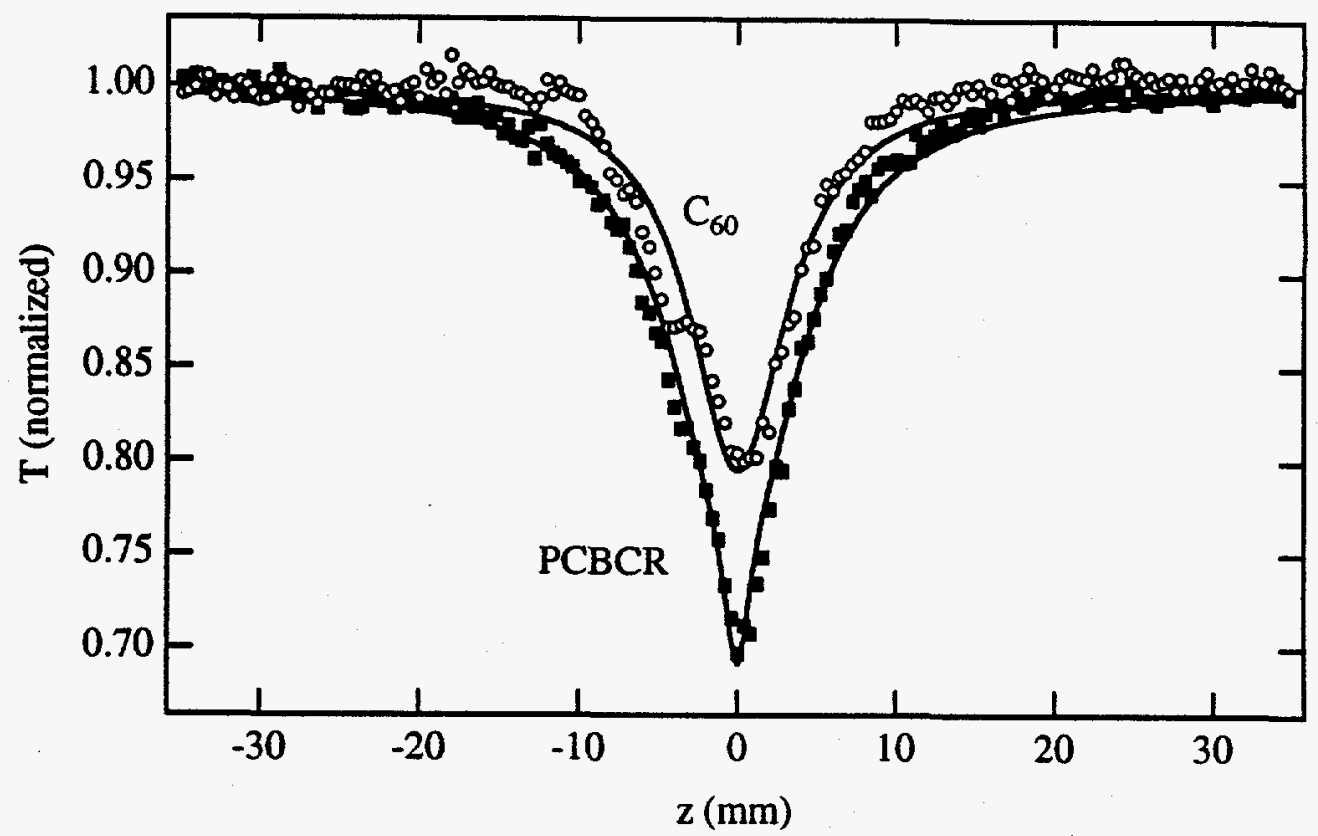

Figure 4. Open aperture Z-scan measurement of the intensity-dependent transmission at $575 \mathrm{~nm}$ for $\mathrm{C}_{60}$ (solid triangles) and PCBCR (solid squares). The solid lines are fits (see text).

Figure 4 shows the open aperture Z-scan data obtained by scanning the samples through the beam focus at a fixed intensity, ${ }^{16}$ for $\mathrm{C}_{60}$ and PCBCR at $575 \mathrm{~nm}$. The solid lines are fits, using an expression $\alpha(\mathrm{I})=\alpha_{0}+\beta_{\text {eff }} \cdot \mathrm{I}$, where $\alpha(\mathrm{I})$ is the intensity-dependent absorption coefficient, $\alpha_{0}$ is the low fluence absorption coefficient, and $\beta_{e f f}$ is the effective two-photon absorption coefficient. In these fits, the intensity as a function of beam position is determined by fitting the data obtained for a reference $\mathrm{ZnSe}$ window, with $\beta_{\text {eff }}$ fixed at the known value $(5.8 \mathrm{~cm} / \mathrm{GW}$ at 532 $\mathrm{nm}) .{ }^{15} \beta_{\text {eff }}$ for the fullerenes is then determined by holding $\mathrm{I}(\mathrm{z})$ fixed at the calibrated value. For the case of a single transition with negligible relaxation within the laser pulsewidth, $\beta_{\text {eff }}$ can be related to an excited-state cross section using the expression $\beta_{\text {eff }}=\sigma_{0} \sigma^{*} \eta \tau / 2 \hbar \omega$, where $\eta$ is the concentration of molecules, $\tau$ is the laser pulswidth, and $\hbar \omega$ is the photon energy at the wavelength of interest. ${ }^{15}$ Table 1 shows the values of $\beta_{e f f}, \alpha_{0}, \sigma^{*}$, and the ratio $\sigma^{*} / \alpha_{0}$, (a measure of the relative optical limiting effectiveness), obtained for $\mathrm{C}_{60}, \mathrm{C}_{78}$, and PCBCR at several wavelengths. While the magnitudes deduced for $\sigma^{*}$ are smaller than those obtained from the high-intensity transmission and excited-state absorption, the trends with wavelength are similar. For $\mathrm{C}_{60}$ and $\mathrm{PCBCR}, \sigma^{*} / \alpha_{0}$ grows larger with longer wavelength beyond $532 \mathrm{~nm}$, consistent with the observation of increasing excited-state absorption, and decreasing ground-state absorption, in this range. For $\mathrm{C}_{78}, \sigma^{*} / \alpha_{0}$ is approximately constant, but increasing slightly, consistent with the observation that both the ground-state and excited-state absorption cross 
sections decrease gradually in this range.

Table 1: Values of $\beta_{\text {eff }}, \alpha_{0}$, and $\sigma^{*}$ obtained for $\mathrm{C}_{60}, \mathrm{C}_{78}$, and PCBCR at $561 \mathrm{~nm}, 575 \mathrm{~nm}$, and $680 \mathrm{~nm}$

\begin{tabular}{cccccc}
\hline \hline Wavelength & Compound & $\beta_{\text {eff }}(\mathrm{cm} / \mathrm{GW})$ & $\alpha_{0}\left(\mathrm{~cm}^{-1}\right)$ & $\sigma^{*}\left(\times 10^{-18} \mathrm{~cm}^{2}\right)$ & $\sigma^{*} / \alpha_{0}\left(\times 10^{-18} \mathrm{~cm}^{3}\right)$ \\
\hline 561 & $\mathrm{C}_{60}$ & 9.6 & 3.4 & 0.39 & 0.11 \\
575 & $\mathrm{C}_{60}$ & 18.5 & 3.4 & 0.72 & 0.21 \\
680 & $\mathrm{C}_{60}$ & 1.8 & 0.45 & 0.45 & 1.00 \\
561 & $\mathrm{C}_{78}$ & 1.9 & 4.7 & 0.05 & 0.011 \\
575 & $\mathrm{C}_{78}$ & 3.2 & 4.1 & 0.11 & 0.027 \\
680 & $\mathrm{C}_{78}$ & 1.3 & 2.0 & 0.07 & 0.035 \\
561 & PCBCR & 14.8 & 3.8 & 0.53 & 0.14 \\
575 & PCBCR & 21.7 & 2.8 & 1.0 & 0.36 \\
680 & PCBCR & 16.2 & 0.70 & 2.61 & 3.71 \\
\hline
\end{tabular}

Figure 5 shows a comparison of the relaxation dynamics of the observed transient photoinduced absorption in a $\mathrm{C}_{60}$ thin film (open squares) with that of $\mathrm{C}_{60}$ in toluene solution (solid circles). The data are normalized, and the entire photoinduced absorption spectrum for each material is integrated over the spectral range of the measurement. The fit to the thin film data (solid line) is a double exponential, with time constants $\tau_{1}=1.5$ ps and $\tau_{2}=20$ ps. The extremely rapid and nonlinear recombination dynamics for $\mathrm{C}_{60}$ thin films at high fluences has been attributed to bimolecular recombination due to exciton-exciton annihilation. ${ }^{20,21}$ The solution data, by contrast, show a very slow decay on this timescale; the integrated excited-state absorption is approximately constant, since the initial relaxation to the triplet state conserves excited-state oscillator strength. Hence, for ns pulses, the excited-state absorption remains large over a broad wavelength range for the duration of the pulse in solution, while the decay back to the ground-state in the solid form is much more rapid than the pulsewidth. In this case, the fact that the optical properties (energy positions and transition moments) of the solution and the solid are very similar (due to the inherently molecular nature of $\mathrm{C}_{60}$ ) does not assure that the limiting performance will be similar also; determination of the recombination dynamics is also essential. Optical limiting measurements of thin films and doped porous glass confirmed this prediction: the optical limiting effectiveness of both was drastically reduced for ns pulses at all wavelengths measured. This phenomenon is independent of the additional triplet quenching in the presence of oxygen ${ }^{3}$ and arises because of the proximity of adjacent fullerenes. ${ }^{21}$ Hence, we conclude that effective solid-state optical limiters using fullerenes must take the form of dispersed solid solutions in a host matrix. ${ }^{2,7,11}$

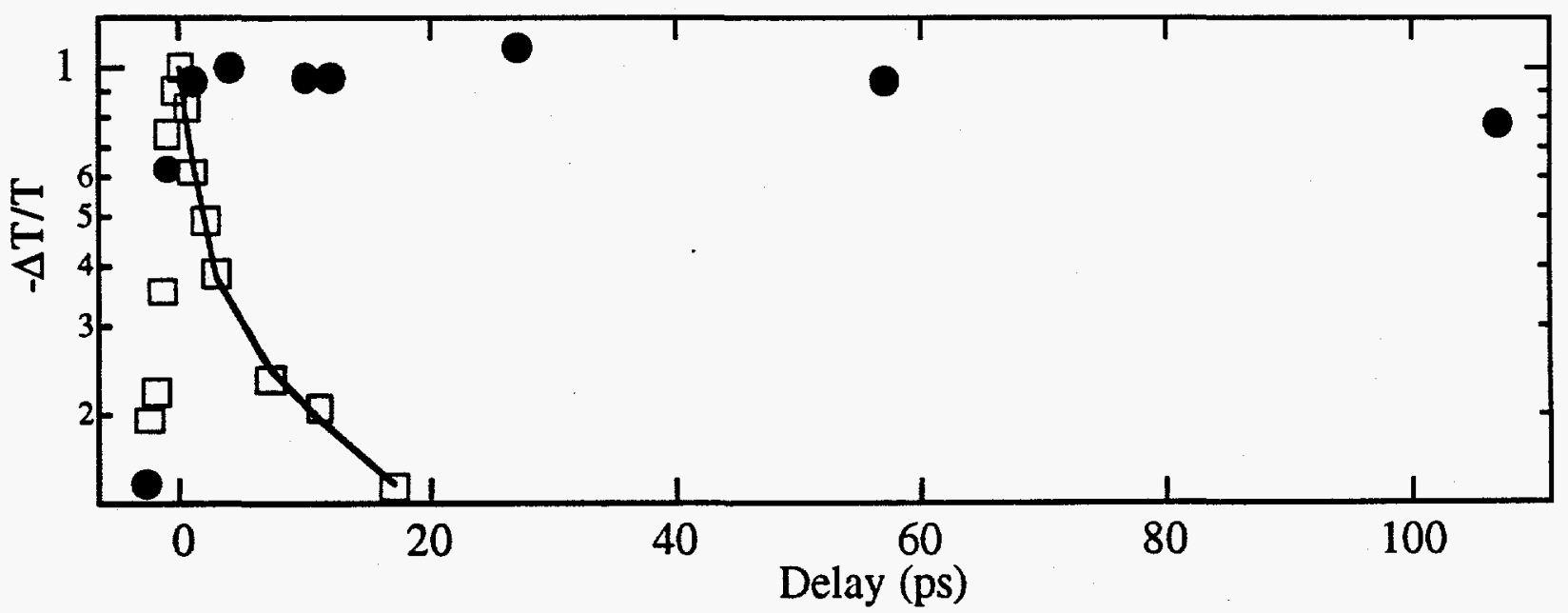

Figure 5. Dynamics of the integrated transient absorption for $\mathrm{C}_{60}$ thin film (open squares) and toluene solution (solid circles). The solid line is a fit to a double exponential, with time constants $\tau_{1}=1.5 \mathrm{ps}$ and $\tau_{2}=20 \mathrm{ps}$. 


\section{CONCLUSION}

We have performed broadband picosecond transient absorption experiments, in conjunction with intensitydependent transmission measurements, to compare the optical limiting performance of $C_{60}$ with several higher fullerenes and substituted $\mathrm{C}_{60}$ derivatives. We find optical limiting in all of the fullerenes measured. The ratio of excited-state to ground-state absorption cross section increases in going from $532 \mathrm{~nm}$ to $700 \mathrm{~nm}$. All of the fullerenes measured display large values of the excited-state cross section from 500-1000 nm. The limiting performance is constrained primarily by solubility and the range over which the ground-state absorption is small but finite (440-630 $\mathrm{nm}$ in $\mathrm{C}_{60}$ ). Based on these considerations, monosubstituted $\mathrm{C}_{60}$ with a substituent chosen for maximum solubility, and $\mathrm{C}_{78}$, are the most promising materials for broadband limiting from 450-1000 nm. Comparison of the optical limiting and excited-state absorption dynamics in solid forms of $\mathrm{C}_{60}$ (thin films and doped porous glass) shows a decreased effectiveness for limiting of ns pulses in the solid state, indicating that solid forms of $\mathrm{C}_{60}$ and derivatives for optical limiting must be dispersed in a host matrix.

\section{ACKNOWLEDGEMENTS}

This work was funded under the auspices of the DOE, through the Laboratory Directed Research and Development program at Los Alamos National Laboratory.

\section{REFERENCES}

[1] L. W. Tutt and A. Kost, "Optical limiting performance of $\mathrm{C}_{60}$ and $\mathrm{C}_{70}$ solutions," Nature 356, pp. 225-226 (1992).

[2] A. Kost, L. W. Tutt, M. B. Klein, T. K. Dougherty, and W. E. Elias, "Optical limiting with $\mathrm{C}_{60}$ in polymethyl methacrylate," Opt. Lett. 18, pp. 334-336 (1993).

[3] Y. Sun, Q. Gong, S. Yang, Y. H. Zou, L. Fei, X. hou, and D. Qiang, "Optical limiting properties of buckminsterfullerene $C_{60} / C_{70}$," Opt. Comm. 102, pp. 205-207 (1993).

[4] D. G. McLean, R. L. Sutherland, M. C. Brant, D. M. Brandelik, P. A. Fleitz, and T. Pottenger, "Nonlinear absorption study of a $\mathrm{C}_{60}$-toluene solution," Opt. Lett. 18, pp. 858-860 (1993).

[5] S. R. Mishra, H. S. Rawat, M. P. Joshi, and S. C. Mehendale, "The role of nonlinear scattering in optical limiting in $\mathrm{C}_{60}$ solutions," J. Phys. B. 27, pp. L157-L163 (1994).

[6] F. Bentivegna, M. Canva, P. Georges, A. Brun, F. Chaput, L. Malier, and J.-P. Boilot, "Reverse saturable absorption in solid xerogel matrices," Appl. Phys. Lett. 62, pp. 1721-1723 (1993).

[7] D. McBranch, B. R. Mattes, A. Koskelo, J. M. Robinson, and S. P. Love, " $\mathrm{C}_{60}$-doped silicon dioxide sonogels for optical limiting," SPIE Vol. 2284 Fullerenes and Photonics, pp. 15-20 (1994).

[8] T. W. Ebbesen, K. Tanigaki, and S. Kuroshima, "Excited-state properties of $\mathrm{C}_{60}$," Chem. Phys. Lett. 181, pp. 501-504 (1991).

[9] R. J. Sension, C. M. Phillips, A. Z. Szarka, W. J. Romanow, A. R. McGhie, J. P. McCauley, Jr., A. B. Smith III, and R. M. Hochstrasser, "Transient absorption studies of $\mathrm{C}_{60}$ in solution," J. Phys. Chem. 95, pp. 6075-6078 (1991).

[10] J. W. Arbogast, A. P. Darmanyan, C. S. Foote, Y. Rubin, F. N. Diederich, M. M. Alvarez, S. J. Anz, and R. L. Whetten, "Photophysical properties of $\mathrm{C}_{60}$," J. Phys. Chem. 95, pp. 11-12 (1991). 
[11] B. R. Mattes, D. McBranch, J. M. Robinson, A. Koskelo, and S. P. Love, "Preparation of fullerene/glass composites," U.S. Patent 5,420,081, May 30, 1995.

[12] J. C. Hummelen and F. Wudl, in preparation.

[13] T. H. Elmer, "Porous and reconstructed glasses," Engineered Materials Handbook, Vol. IV, pp. 427-432, ASM International, Materials Park, Ohio 1992.

[14] N. F. Borrelli, C. Smith, and D. W. Smith, "Fullerenes entrapped in porous glass," MRS Spring Meeting proceedings, April 1994.

[15] E. W. Van Stryland, M. Sheik-Bahae, A. A. Said, and D. J. Hagan, "Characterization of nonlinear optical absorption and refraction," Prog. Crystal Growth and Charact. 27, pp. 279-311 (1993).

[16] M. Sheik-Bahae, A. A. Said, T.-H. Wei, D. J. Hagan, and E. W. Van Stryland, "Sensitive measurements of optical nonlinearities using a single beam," IEEE J. Quant. Electr. 26, pp. 760-767 (1990).

[17] Y. Wang, J. M. Holden, A. M. Rao, P. C. Eklund, U. D. Venkateswaran, D. Eastwood, R. L. Lidberg, G. Dresselhaus, and M. S. Dresselhaus, "Optical absorption and photoluminescence in pristine and photopolymerized $\mathrm{C}_{60}$ solid films," Phys. Rev. B51, pp. 4547-4556 (1995).

[18] L. W. Tutt and T. F. Boggess, "A review of optical limiting mechanisms and devices using organics, fullerenes, semiconductors, and other materials," Prog. Quant. Elect. 17, pp. 299-338 (1993).

[19] J. R. Heflin, S. Wang, D. Marciu, J. W. Freeland, and B. Jenkins, "Dispersion of Optical Limiting in $\mathrm{C}_{60}$ and Phthalocyanines," Polym. Prep. 35, 238-9 (1994).

[20] S. L. Dexheimer, W. A. Varecka, C. V. Shank, D. Mittelman, and A. Zettl, "Nonexponential relaxation in solid $\mathrm{C}_{60}$ via time-dependent singlet exciton annihilation," Chem. Phys. Lett. 235, 552 (1995).

[21] S. R. Flom, F. J. Bartoli, H. W. Sarkas, C. D. Merritt, and Z. H. Kafafi, "Resonant nonlinear optical properties and excited-state dynamics of pristine, oxygen-doped, and photopolymerized $\mathrm{C}_{60}$ in the solid state," Phys. Rev. B 51, pp. 11376-11381 (1995). 